GLENN, E, M., \& GRAY, J. Effect of various hormones on the growth and histology of the gerbil (Meriones unguiculatus) abdominal sebaceous gland pad, Endocrinology, 1965, 76, 1115-1123.

GLICKMAN, S. E., FRIEND, L., \& MORRISON, B. A. Shredding of nesting material in the Mongolian getbil. Percept. mot. Skills, 1967, 24, $473-474$.

HIGGINS, T., GLICKMAN, S. E., \& ISAACSON, R. The effects of hippocampal lesions on behavior patterns of the Mongolian gerbil (Meriones unguiculatus), Psychon. Bull., 1967, 1, 26.

LINDZEY, G., THIESSEN, D. D., \& TUCKER, A. Development and hormone control of territorial marking in the male Mongolian gerbil (Meriones unguiculatus). Developm. Psychobiol., 1968, in press.

MARLER, P. R., \& HAMILTON, W. J. III. Mechanisms of animal behavior. New York: Wiley, 1966.

MARSTON, J. H., \& CHANG, M. C. The breeding, management and reproductive physiology of the Mongolian gerbil (Meriones unguiculatus). Lab. Anim Care, 1965, 15, 34-48.

MILNE-EDWARDS, A. Observations sur quelques mammifers du Nond de la Chine, Ann. Sci Naturalist (Zool.), 1867, 7, 375-377.

MITCHELL, O. G. Effect of castration and transplantation on ventral gland of the gerbil. Proc. Soc. Exp. biol. Med., 1965, 119, 953-955.

MITCHELL, O. G. The supposed role of the gerbil ventral gland in reproduction. J. Mammal., 1967, 48, 142.

MYKYTOWYCZ, R. Further observations on the territorial function and histology of the submandibular cutaneous (chin) glands in the rabbit, Oryctolagus cunicular (L.). Anim. Behov., 1965, 13, 400-412.

NAUMAN, D. J. The Mongolian gerbil as an experimental animal in behavioral research. Paper read at North and South Dakota Bi-State Psychological Convention, Aberdeen, South Dakota, 1963.

NAUMAN, D. J. Open field behavior of the Mongolian gerbil. Psychon. Sci, 1968, 10, 163-164.
PARKES, A. S., BRUCE, H. M. Olfactory stimuli in mammalian reproduction. Science, 1961, 134, $1049-1054$.

PEARSON, O. P. Scent glands of the short-tailed shrew. Anat. Rec., 1946, 94, 615-629.

ROUTTENBERG, A., \& DRAMIS, R. C. "Foot-stomping" in the gerbi: rewarding brain stimulation, sexual behaviour, and foot shock. Nature, $1967,214,173-174$.

SCHWENTKER, V. The gerbil-a new laboratory animal, minois Vet, $1963,6,5-9$.

SCHWENTKER, V. The gerbil: an annotated bibliography. Available from Tumblebrook Farm, Inc., Brant Lake, New York, 1968.

THIESSEN, D. D., LINDZEY, G., BLUM, S., TUCKER, A., \& FRIEND, H. Visual behavior of the Mongolian gerbil (Meriones unguiculatus). Psychon. Sci, 1968, 11, 23-24.

THIESSEN, D. D., FRIEND, H., \& LINDZEY, G. Androgen control of territorial marking in the Mongolian gerbil. Science, 1968, 160, $432-434$. $432-434$.

ULRICH, R. Pain as a cause of aggression. Amer. Zoologist, 1966, 6, 643-662.

WALTERS, G. C., PEARL, J., \& ROGERS, J. V. The gerbil as a subject in behavioral research. Psychol. Rep., 1963, 12, 315-318.

WEBSTER, D. B., \& CACCAVALE, K. L. Roles of eyes and vibrissae in maze running behavior of gerbils and kangaroo rats. Amer. Zoologist, $1966,6,23$

\section{NO'TE}

1. This work was supported by Grant MH 1407-01 and Research Development Award, MH 11, 174-01, from the National Institute of Mental Health.

\title{
An improved shocking surface for pigeons and rats'
}

\section{JOSEPH J. WALKER AND M. E. BITTERMAN, BRYN MAWR COLLEGE, Bryn Mawr, Pa.}

$A$ resistive shocking surface and an appropriate power supply are described. The efficacy of the system is illustrated with some data on the activity of pigeons and rats as a function of the voltage applied.

The conventional shocking grid is unsuitable for the pigeon because when the bars are far enough apart to prevent shorting by fecal material the animal can avoid shock by standing on a single bar. Wing clips are irritative and do not make dependable contact with the skin. Subdermal electrodes are difficult to implant properly, and the internal leads to them are easily broken off in the course of activity. In work with the rat, the conventional grid is reasonably satisfactory if used with a scrambler to eliminate the possibility that the animal can stand on two equipotential bars, but the animal still can avoid shock by rearing up on a single bar. The attachment of shocking electrodes to the skin is more difficult for rats than for pigeons.

An earlier report from this laboratory describes a resistive shocking technique suitable both for pigeons and for rats (Longo, Holland, \& Bitterman, 1960). The principle is simple: when a voltage is applied across a resistive surface on which an animal is standing, the animal is connected in parallel with the circuit through the surface. The results reported in the earlier paper were obtained with painted surfaces into which holes were drilled to permit the running off of urine and feces. The resistive paints used were made by adding powdered graphite to a binder such as black asphaltum or a solution of styrofoam in methyl-ethylketone. Such surfaces are easy to construct, but they are unsatisfactory because their resistance changes with continued use, both as a function of cleaning and as a function of current flow. Pending the development of a suitable paint, we now use a more elaborate surface, somewhat difficult to construct, but perfectly stable.

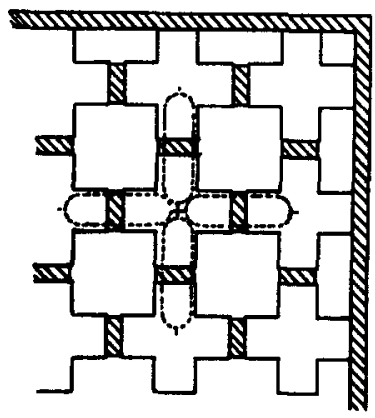

Fig. 1. A section of the shocking surface. Above: top view. The hatched areas are plastic dividers and border pieces; the crosses are brass electrodes; the squares are openings which permit the running off of urine and feces; the broken lines show the ceramic resistors wired to the crosses on the under side. Below: side view showing crosses, dividers, and resistors.

Diagrammed in Fig. 1 is a section of the $103 / 4 \times 91 / 2$-in. surface for which data are reported here. The surface is a $19 \times 17$ matrix of $1 / 2$-in. brass crosses (arms $3 / 32$ in. wide) separated by $1 / 16$-in. plastic dividers. The thickness of the surface is $1 / 2$ in. On the under side, each cross is connected to each adjacent cross by a $15 \mathrm{~K}$, $5 \%, 1 / 2-W$ ceramic resistor, and the properties of the network are such that the resistance between adjacent crosses is about $4 \mathrm{~K}$. 
Fig. 2. The shocking circuit and the pattern of connection to the shocking surface. A variac $(V)$ powers a 2:1 stepup transformer, to whose secondary four Stancor P-8150 1550-V transformers are connected in parallel. Each choke is $200 \mathrm{H}$, and each capacitor is $.04 \mu \mathrm{f}$. Connections to the surface are made at points $\mathbf{A}, \mathbf{A}^{\prime}, \ldots . \mathbf{D}, \mathbf{D}^{\prime}$.
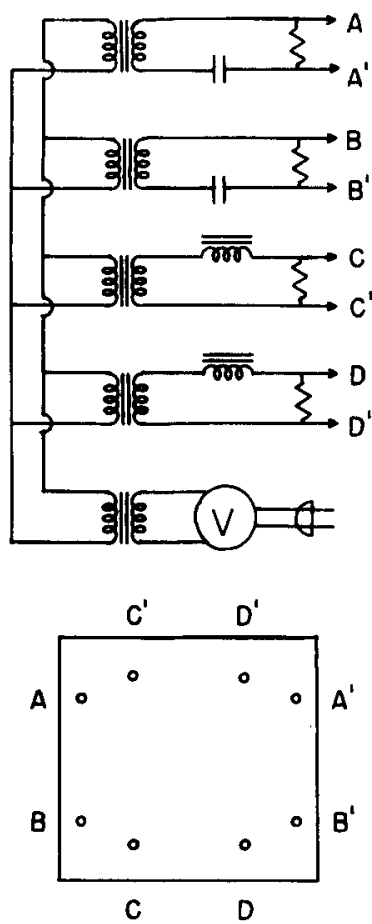

The surface rests on banana plugs soldered to its underside at eight points, whose coordinates in columns and rows of crosses (19 columns and 17 rows) reading from left to right and from top to bottom are as follows: 6-3 (six columns from the left, three rows down), 14-3, 2-5, 18-5, 2-13, 18-13, 6-15, and 14-15. The plugs are inserted into banana jacks set at corresponding.points in a Plexiglas base. The jacks are wired to the power supply as shown in Fig. 2.

If a voltage difference is simply applied at two opposite sides of a resistive surface, the amount of current received by the animal will vary with its orientation. For example, a pigeon will receive more shock if the line between its feet is parallel to the line between the points at which the voltage is applied than if the two lines are perpendicular. To minimize the effect of orientation, a rotating field may be obtained by phasing two independent fields which are at right angles to each other in such a way that one reaches its peak value when the other is at zero. Rotation may be accomplished by retarding one field with a choke and advancing the other with a capacitor. In the circuit used here, two connections are made to each side of the surface in order to promote a more uniform distribution of current. Each choke is $200 \mathrm{H}$, and each capacitor is $.04 \mu \mathrm{f}$. The primaries of four 1550-V transformers (Stancor P-8150) are connected in parallel to the secondary of a 2:1 step-up transformer whose primary is powered by a variac. Shock levels are specified in terms of variac settings.

To study the efficacy of the system, the shocking surface was set on a ball-bearing activity platform like that described by Davis \& Ellison (1964), with a $1 / 2$-in. sheet of foam rubber between the surface and the platform. The platform rested on the floor of a ventilated picnic chest. Movements of the platform were detected, not with the pendular contact of Davis and Ellison, but by means of a thin rod running from the platform to the needle-holder of an Astatic 16 phonograph cartridge. The output of the cartridge, amplified and integrated by the method of Longo \& Bitterman (1959), was used to step a cumulative recorder. The Ss were four white Carneaux pigeons and four albino rats. For several days prior to testing, the feet of the pigeons were treated with a callous-remover. On test days, the feet were simply brushed with dry paper toweling just before the animal was put into the chamber. (The resistance of the feet can be reduced by wetting them or by rubbing them with electrode paste, but the effect is only temporary, and the resistance will increase again in the course of even a brief experimental session.) The feet of the rats were entirely untreated.

The first step in the testing procedure was to determine voltage thresholds. Placed in the darkened chamber, the animals were shocked on a flat VI-2 min schedule (range, 90-210 sec). The duration of each shock was $2 \mathrm{sec}$, and the variac setting was increased from zero in stepwise fashion until a value was found that produced a response on $100 \%$ of trials. To begin with, many of the animals were quite active in the intervals between shocks, but as the testing proceded interval-activity diminished, and the probability that the animal would already be active at the time shock was introduced became quite small. For the pigeons, the lowest variac setting which produced consistent response in all four Ss was $60 \mathrm{~V}$. For the rats, whose skin resistance was considerably lower, it was only $10 \mathrm{~V}$.

The next step in the testing procedure was to determine if the extent to which the animals were activated by the shock could be controlled effectively by variation in voltage. To that end, each animal was tested at four variac settings $(10,20,30$, and $40 \mathrm{~V}$ for the rats; $60,73,86$, and $100 \mathrm{~V}$ for the pigeons) in two sessions. In each session, the animal was shocked eight times on the Vl-2 min schedule, two times at each voltage in a balanced order which was different for each of the four animals of a given species. The duration of each shock was 2 sec. The cumulative records for one animal of each species are reproduced in Fig. 3. In
Fig. 3. Cumulative records of activity for one pigeon and one rat in each of two sessions. The diagonal pips show the points at which shock was administered. The adjacent numbers are the variac settings.

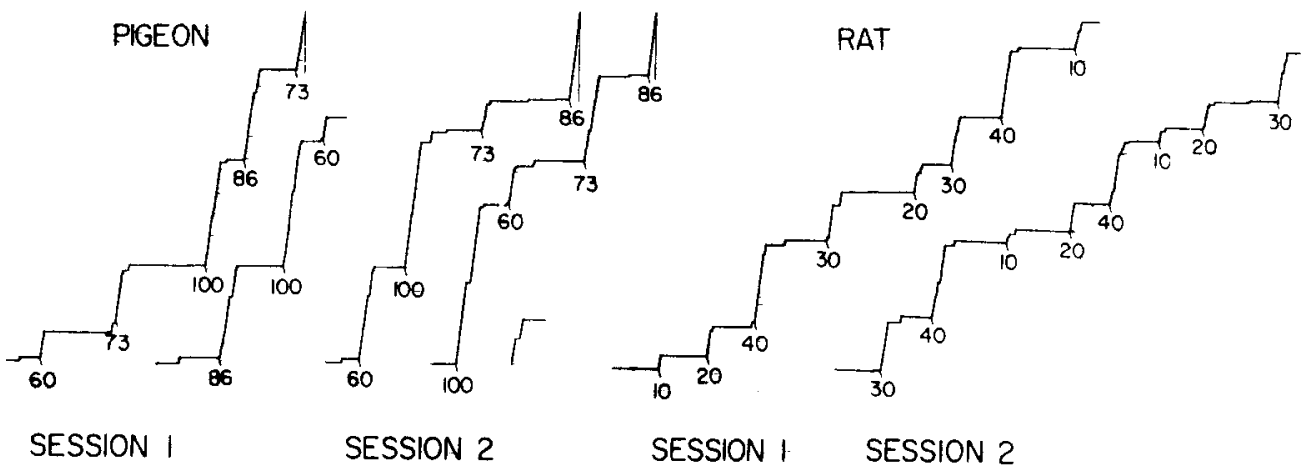


each case, they show systematic increases in activity with voltage. The rate of response was constant from voltage to voltage; increasing the voltage tended simply to increase the duration of response. The same may be said of the difference between species; the greater activity of the pigeons (evident even at the lowest voltage) could be traced to a difference in duration rather than rate of response.

The mean curves for the four rats and the four pigeons are plotted in Fig. 4. To avoid the difficulty of judging when each response terminated, we simply measured the total amount of activity between shocks. Although the interval between shocks was not constant, the animals typically were inactive during the latter portion of each interval. Furthermore, the length of the

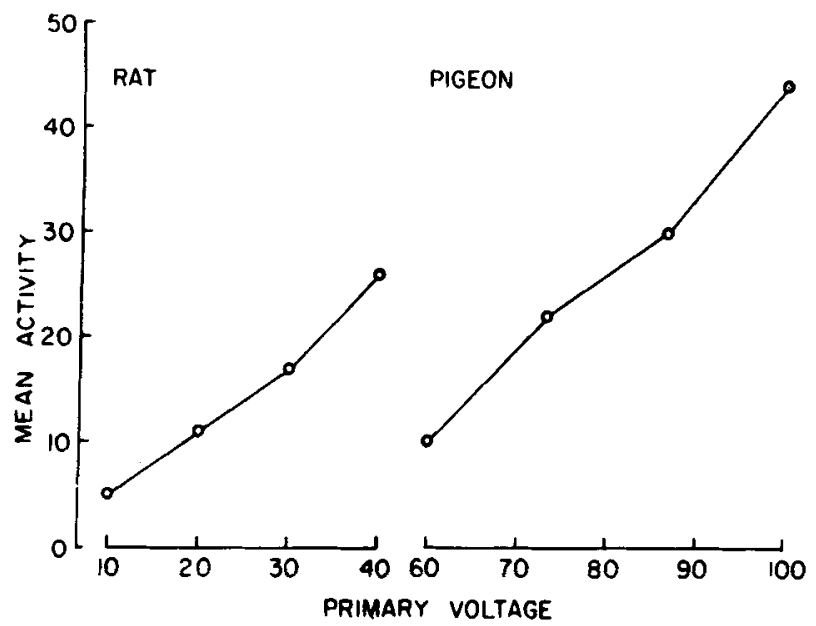

Fig. 4. Mean amount of activity as a function of voltage in four rats and four pigeons. interval was balanced with respect to voltages and animals. Over the ranges measured, the mean curves show a substantially linear relation of activity to voltage which is evident also in the individual data.

The shocking surface described here, which is satisfactory both for rats and pigeons, was constructed after tests of another surface, which proved satisfactory for rats but not for pigeons-a $15 \times 13$ matrix of 7/16-in. brass crosses separated by $1 / 4$-in. plastic dividers, with the same area as the surface which has already been described. The square openings between the crosses are $1 / 2$ in. rather than $3 / 8$ in. on a side. This less dense surface fails occasionally with pigeons even at high voltages, apparently because it is possible for the animal to avoid contact with more than one of the crosses. A single surface which can be used for both species is convenient, of course, but the less dense surface has two minor advantages in work with rats. One is that it is somewhat easier to construct. Another is that the probability of local shorting by fecal material is considerably less, although it should be noted that shorting does not prevent shock. Shock fails only when a large enough area of the surface is shorted that the animal can stand on it alone, and that never has happened in our experiments.

\section{REFERENCES}

LONGO, N., \& BITTERMAN, M. E. Improved apparatus for the study of learning in fish. Amer. J. Psychol., 1959, 72, 616-620.

LONGO, N., HOLLAND, L. R., \& BITTERMAN, M. E. The resistive sheet: a gridless and wireless shocking technique. Amer. J. Psychoh, 1961, 74, 612618.

DAVIS, J. D., ELLISON, G. D. A general purpose activity recorder with variable sensitivity.J. exp. Anal Behav., 1964, 7, 117-118.

\section{NOTE}

1. This work was supported by Contract Nonr 2829(01) with the Office of Naval Reseanch. 